\title{
Tests of reinforced concrete short columns laterally strengthened with wire rope units and steel elements
}

\author{
K.-H. Yang* and A. F. Ashour $\dagger$ \\ Mokpo National University; University of Bradford
}

The current paper presents a simple unbonded-type column strengthening technique with wire rope units and few steel elements. Eleven short columns were strengthened using the proposed procedure and tested under monotonic concentric axial loads. The main variables investigated to evaluate the confinement effectiveness of strengthened concrete columns were the volume ratio, prestress, diameter, spacing and configuration of wire rope units. The strength gain factor and ductility ratio increased with the increase of volume ratio of wire ropes. The prestress applied to wire ropes had little influence on the strength gain factor but the ductility ratio decreased with the increase of prestress in the wire ropes, owing to earlier rupture of wire ropes. At the same volume ratio of wire ropes, the maximum strength of columns was nearly independent on the configuration of the wire ropes, but higher ductility was exhibited by columns strengthened with rectangular spiral-type wire ropes than by columns strengthened with hoop-type wire ropes, until rupture of the wire ropes. The strength gain factor and ductility ratio of strengthened columns were compared with those of tied columns tested in a previous study. The load capacity of strengthened columns was also predicted using the ACI 318-05 equation modified to reflect the load-carrying effect of steel elements. A much higher strength gain factor and ductility ratio were exhibited by strengthened columns than tied columns having the same lateral reinforcement, except for strengthened columns with wire rope spacing above 0.5 times core width. The axial load capacity of strengthened columns was higher than that of unstrengthened columns by 5-20\%, and could be reasonably predicted using the modified ACI 318-05 equation.

\section{Introduction}

Reinforced concrete columns carrying axial compressive loads with or without moment require enough ductility to withstand large deformations as well as to resist applied loads. At large deformations, spalling of cover concrete would likely be extensive, and the load capacity and ductility of columns would greatly depend on the effectiveness of core concrete confined by hoops. It is generally accepted that a proper arrangement of lateral reinforcement, such as hoops and spiral bars, results in improved strength and ductility of the confined concrete. ${ }^{1-7}$

\footnotetext{
* Department of Architectural Engineering, Mokpo National University, Mokpo, Jeonnam, South Korea.

$\dagger$ EDT1, School of Engineering, Design and Technology, University of Bradford, Bradford, UK.
}

(MCR 600013) Paper received 2 November 2006; last revised 18 March 2007; accepted 26 March 2007
With a growing interest in restoration of concrete structures, effective strengthening methods to enhance the strength and ductility of existing reinforced concrete columns were developed. In the existing carbon fibre sheet or steel plate strengthening method, the strengthening materials would debond from concrete surfaces in large deformations or long-term behaviour owing to differential linear expansion coefficients among concrete, strengthening material and adhesive. As a result, few investigations on unbonded-type strengthening method were published. Teng et al. ${ }^{8}$ and Kim et al. ${ }^{9}$ showed that the externally unbonded-type stirrups were highly economical and structurally efficient in enhancing concrete beam capacity.

The present investigation reports the testing of 11 short concrete columns strengthened using unbonded wire rope tie units and fractions of steel elements. The main variables investigated were the volume ratio, prestress, diameter, spacing, and configuration of wire rope tie units. The strength gain factor in core concrete of 
strengthened columns was compared with predictions obtained from the empirical models of Kent and Park, ${ }^{2}$ Saatcioglu and Razvi ${ }^{4}$ and Sheikh and Uzumeri, ${ }^{7}$ based on test results of tied columns. The strength gain factor and ductility ratio of the strengthened columns were also compared with those of conventionally tied columns. ${ }^{10}$

\section{Research significance}

Although the bonded-type strengthening method has maintenance and environmental problems, very few, if any, tests of columns having externally unbonded-type strengthening method have been published. To enhance the strength and ductility of existing reinforced concrete columns, an effective unbonded-type strengthening method having wire rope units and steel elements is proposed. Higher strength enhancement and ductility is exhibited by columns strengthened with the developed strengthening method than in tied columns. The axial load capacity of strengthened columns was also higher than that of unstrengthened columns by $5-20 \%$, and could be reasonably predicted using the modified ACI $318-05^{11}$ equation.

\section{Experimental investigation}

\section{Strengthening procedure}

Wire ropes, which play an important role in various offshore and onshore applications, have many advan- tages such as being lightweight, of high-strength and high flexibility. In the present investigation, the significance and shortcomings of using the wire rope technique as external lateral reinforcement to enhance the strength and ductility of reinforced concrete columns are explored. Fig. 1 shows the details of unbonded-type wire rope units and few steel elements for strengthening of reinforced concrete columns. To maintain the section area of existing columns, the wire rope units and steel sections were installed after the removal of cover concrete. T-shaped and L-shaped steel sections having a $2.1 \mathrm{~mm}$ thickness were placed along intermediate and corner longitudinal reinforcing bars, respectively. The flange width of T-shaped and L-shaped steel sections was $20 \mathrm{~mm}$, so that individual longitudinal reinforcement could have enough support to prevent buckling of longitudinal reinforcement and enhance bearing capacity of concrete against wire ropes after spalling of cover concrete. The web height of T-shaped steel elements was determined to leave no gap between wire ropes and steel elements. As a result, all steel elements could be fixed in place by wire rope units owing to the prestressing force in wire ropes. A wire rope unit consists of a wire rope and one set of eye-bolt, washer and nut. One end of the wire rope is connected to a $10 \mathrm{~mm}$ diameter eye-bolt and the other is joined to a washer as shown in Fig. 1. Both ends of wire ropes are coupled at the L-shaped steel elements and prestressed by tightening of nuts, similar to the torque control method in high-strength bolts. After the designed prestress force in wire ropes achieved owing to the tightening of nuts, cover concrete

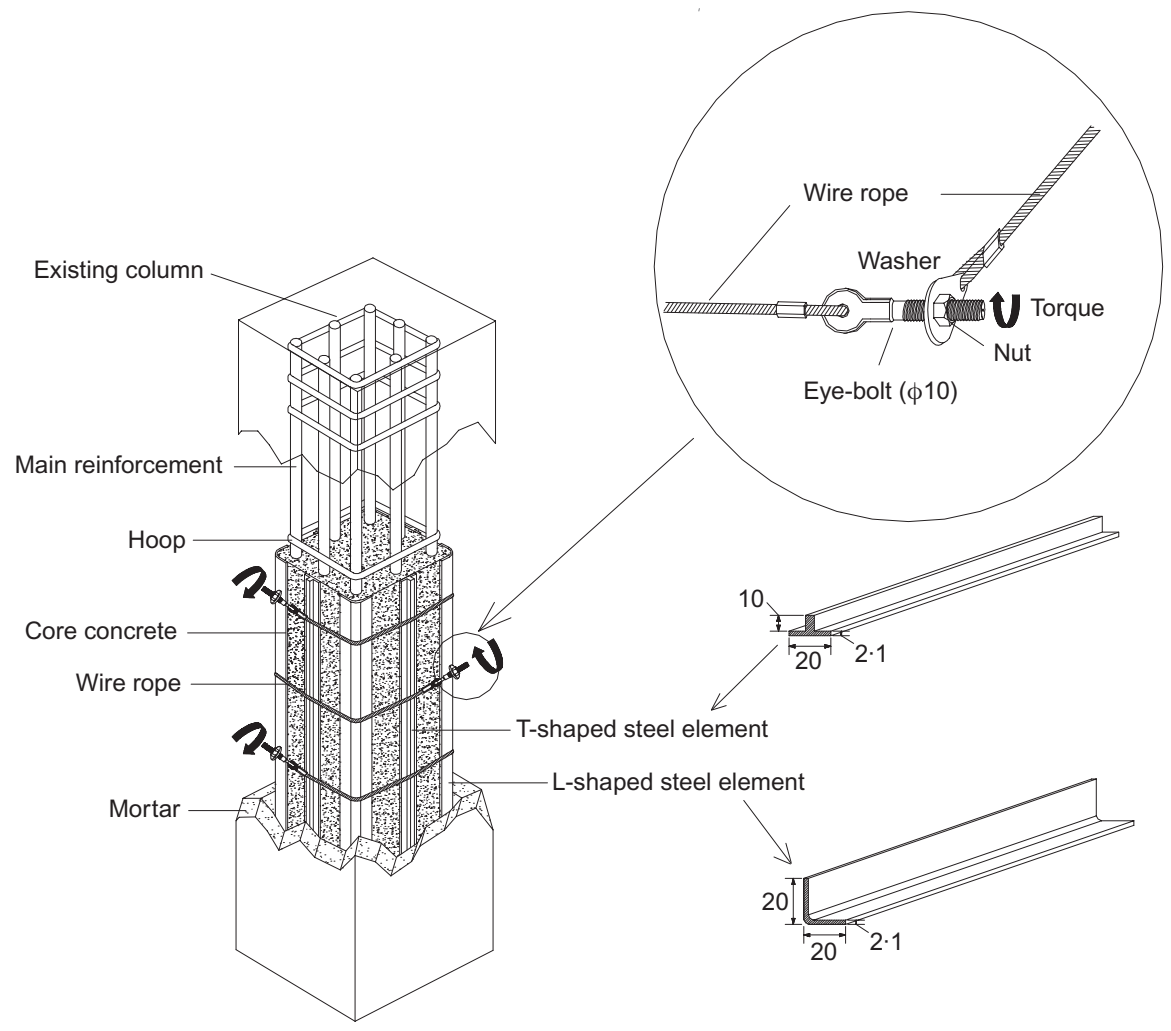

Fig. 1. Details of wire rope units used for reinforced concrete column strengthening (dimensions in mm) 
was constructed using cement mortar according to the size of the existing column section. When the strengthened concrete column is axially loaded, all arranged wire ropes act as hoops to confine concrete, and steel elements can also carry axial force.

In the proposed wire rope units, the prestressing tensile effect is exerted on wire ropes by tensile force in eye-bolts owing to tightening of nuts, which can be controlled by the externally applied torque. If the friction coefficient is constant, the relation between the externally applied torque $T$ and tensile force $N$ acting on a bolt can be written as follows ${ }^{12}$

$$
T=k d_{\mathrm{b}} N
$$

where $d_{\mathrm{b}}$ is bolt diameter and $k$ is a torque coefficient, which is dependent on the friction coefficient and geometrical conditions of the thread in bolts and nuts. From the test results described in a companion paper, ${ }^{9}$ the torque coefficient $k$ in the developed wire rope unit can be reasonably assumed as $0 \cdot 3$. Losses of prestress in wire ropes owing to deformation of concrete and relaxation of wire ropes would occur; however, this has a very small effect and is negligible.

\section{Test specimens}

Eleven short columns were strengthened and tested under monotonic axial loads. Details of geometrical

Table 1. Details of test specimens

\begin{tabular}{|c|c|c|c|c|c|c|c|}
\hline \multirow[t]{2}{*}{ Specimen } & \multicolumn{7}{|c|}{ Details of wire rope units } \\
\hline & Configuration & $d_{\mathrm{w}}: \mathrm{mm}$ & $s_{\mathrm{w}}: \mathrm{mm}$ & $\rho_{\mathrm{w}}$ & $F_{\mathrm{i}}: \mathrm{kN}$ & $T: \mathrm{Nm}$ & $f_{\mathrm{i}} / f_{\mathrm{pu}}$ \\
\hline $\mathrm{C} 1$ & None & - & - & - & - & - & - \\
\hline $\mathrm{C} 2$ & Hoop type & $4 \cdot 8$ & 75 & 0.0035 & 5 & 15 & $0 \cdot 26$ \\
\hline $\mathrm{C} 3$ & & $3 \cdot 2$ & 35 & 0.0036 & & 7 & 0.54 \\
\hline $\mathrm{C} 4$ & & $6 \cdot 3$ & 130 & 0.0035 & & 25 & $0 \cdot 15$ \\
\hline $\mathrm{C} 5$ & & $4 \cdot 8$ & 50 & 0.0053 & & 15 & 0.26 \\
\hline C6 & & & 100 & 0.0027 & & & \\
\hline $\mathrm{C} 7$ & & & 150 & 0.0018 & & & \\
\hline $\mathrm{C} 8$ & & & 75 & 0.0035 & $8 \cdot 3$ & 25 & 0.43 \\
\hline C9 & & & 75 & $0 \cdot 0035$ & $11 \cdot 6$ & 35 & $0 \cdot 60$ \\
\hline $\mathrm{C} 10$ & Spiral type & $3 \cdot 2$ & 70 & $0 \cdot 0018$ & 5 & 7 & $0 \cdot 54$ \\
\hline C11 & & & 140 & 0.0009 & & & \\
\hline
\end{tabular}

$d_{\mathrm{w}}=$ diameter of wire rope, $s_{\mathrm{w}}=$ spacing of wire rope, $\rho_{\mathrm{w}}=$ volume ratio of wire rope $\left[=\left(4 D_{\mathrm{c}} A_{\mathrm{w}}\right) /\left(D_{\mathrm{c}}^{2} s_{\mathrm{w}}\right)\right], A_{\mathrm{w}}=$ net area of wire rope, $D_{\mathrm{c}}$ $=$ core width, $F_{\mathrm{i}}=$ initial tensile force of wire rope, $T=$ initial torque value applied in bolt, $f_{\mathrm{i}}=$ prestress applied in wire rope, and $f_{\mathrm{pu}}=$ tensile strength of wire rope.

In all test specimens, $f_{\mathrm{c}}^{\prime}, f_{\mathrm{m}}^{\prime}, p_{\mathrm{s}}$ and $p_{\mathrm{p}}$ were constant at $22.7 \mathrm{MPa}, 21.4 \mathrm{MPa}, 0.023$ and 0.014 , respectively, where, $f_{\mathrm{c}}^{\prime}=$ cylinder compressive strength of concrete, $f_{\mathrm{m}}^{\prime}=$ cylinder compressive strength of mortar, $p_{\mathrm{s}}=$ longitudinal reinforcement ratio $\left(=A_{\mathrm{s}} / B D\right), A_{\mathrm{s}}=$ total area of longitudinal reinforcement, $B=$ section width, $D=$ section depth, $p_{\mathrm{p}}=$ steel element ratio $\left(=A_{\mathrm{sp}} / B D\right), A_{\mathrm{sp}}=$ total area of T-shaped and Lshaped steel elements.

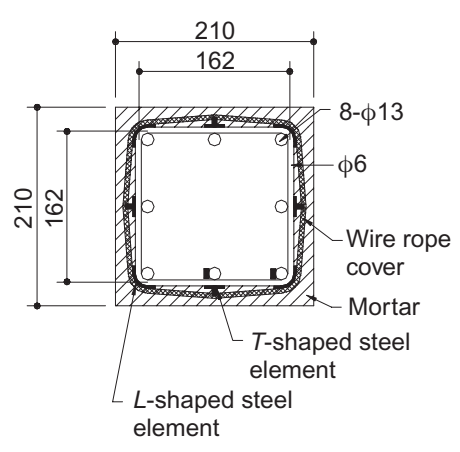

(a)

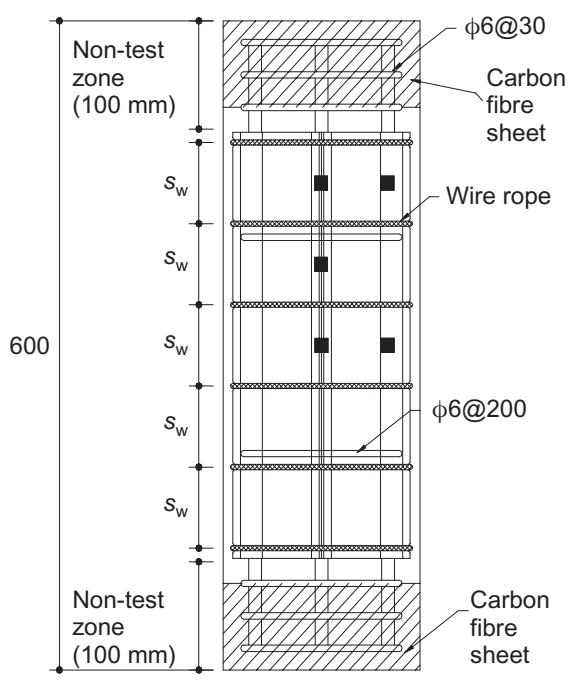

(b)

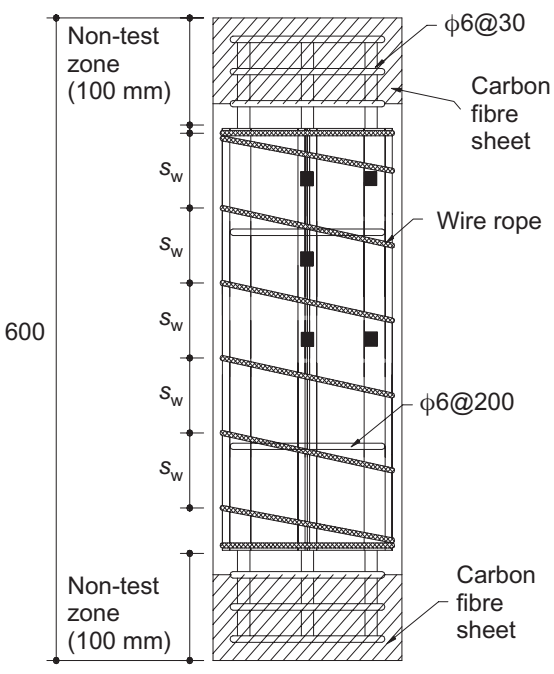

(c)

Fig. 2. Specimen details and arrangement of wire rope units and steel elements: (a) column section; (b) with rectangular hooptype wire rope units; (c) with rectangular spiral-type wire rope units. (- indicates positions of ERS gauges bonded to longitudinal reinforcement and steel elements; dimensions in $\mathrm{mm}$ ) 
dimensions and wire rope units arranged in test specimens are given in Table 1 and Fig. 2. All tested columns were $210 \mathrm{~mm}$ square and $600 \mathrm{~mm}$ high. The concrete core size measured from the centre of the internal steel hoop was kept constant at $162 \mathrm{~mm} \times$ $162 \mathrm{~mm}$. Eight longitudinal reinforcing bars of $13 \mathrm{~mm}$ diameter were placed inside the hoop for all specimens, producing a longitudinal reinforcement ratio $p_{\mathrm{s}}$ (= $A_{\mathrm{s}} / B D$ ) equal to 0.023 , where $A_{\mathrm{s}}$ is the longitudinal reinforcement area, $B$ is the section width and $D$ is the section depth. The main variables investigated were the volume ratio, prestress, diameter, spacing and configuration of wire rope units. Specimen C1 was an unstrengthened, control column. For specimen $\mathrm{C} 2$, the diameter, spacing, and initial tensile force owing to prestressing of wire rope units were $4.8 \mathrm{~mm}, 75 \mathrm{~mm}$ and $5 \mathrm{kN}$, respectively. Specimens $\mathrm{C} 3$ and $\mathrm{C} 4$ were designed to evaluate the effect of diameter and spacing of wire rope units at the same volume ratio $\rho_{\mathrm{w}}[=$ $\left.\left(4 D_{\mathrm{c}} A_{\mathrm{W}}\right) /\left(D_{\mathrm{c}}^{2} s_{\mathrm{W}}\right)\right]$ of 0.003 and initial tensile force $F_{\mathrm{i}}$ of $5 \mathrm{kN}$ in wire ropes, where $A_{\mathrm{w}}$ is the net area of a wire rope, $D_{\mathrm{c}}$ is the concrete core width and $s_{\mathrm{W}}$ is spacing of wire ropes. For specimens C5, C6 and C7 the spacing of wire ropes was varied at the same $4.8 \mathrm{~mm}$ diameter and $5 \mathrm{kN}$ initial prestressing tensile force in wire ropes. The initial tensile force was varied in specimens $\mathrm{C} 8$ and $\mathrm{C} 9$ at the same $4.8 \mathrm{~mm}$ diameter and $75 \mathrm{~mm}$ spacing of wire ropes. Specimens C10 and C11 had spiral-type wire ropes of a smaller diameter of $3.2 \mathrm{~mm}$ to allow easy arrangement of rectangular spiral-type wire ropes.

All specimens except unstrengthened column $\mathrm{C} 1$ had the same T-shaped and L-shaped steel elements along the individual longitudinal reinforcement, as shown in Fig. 2. As a result, a steel element ratio $p_{\mathrm{p}}\left(=A_{\mathrm{sp}} / B D\right)$ was $0 \cdot 014$, where $A_{\text {sp }}$ is the total area of T-shaped and L-shaped steel elements. All wire rope units and steel elements were installed only within the test region of $400 \mathrm{~mm}$, as shown in Fig. 2. Deformed steel bars of $6 \mathrm{~mm}$ diameter were arranged at spacings of $200 \mathrm{~mm}$ as internal hoops in all test specimens for the test region, and both ends outside the test regions were strengthened with carbon fibre sheets to prevent premature failure in these regions.

\section{Material properties}

Design compressive strength of concrete and mortar was selected as $21 \mathrm{MPa}$ to simulate the strength of old, deteriorated concrete. Control specimens of $100 \mathrm{~mm}$ diameter $\times 200 \mathrm{~mm}$ high cylinders were cast and cured simultaneously with columns to determine the compressive strength of concrete and mortar. Fig. 3 shows a typical stress-strain relationship of concrete and mortar used in the test specimens. Concrete and mortar strengths obtained from the compressive test were $22.7 \mathrm{MPa}$ and $21.4 \mathrm{MPa}$, respectively, for all column specimens.

Figure 4 and Table 2 show the stress-strain relation-

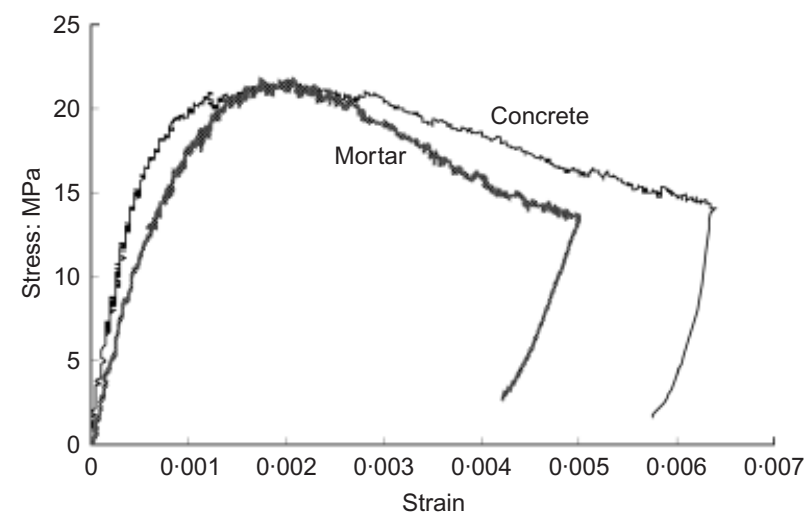

Fig. 3. Stress-strain relationships of concrete and mortar

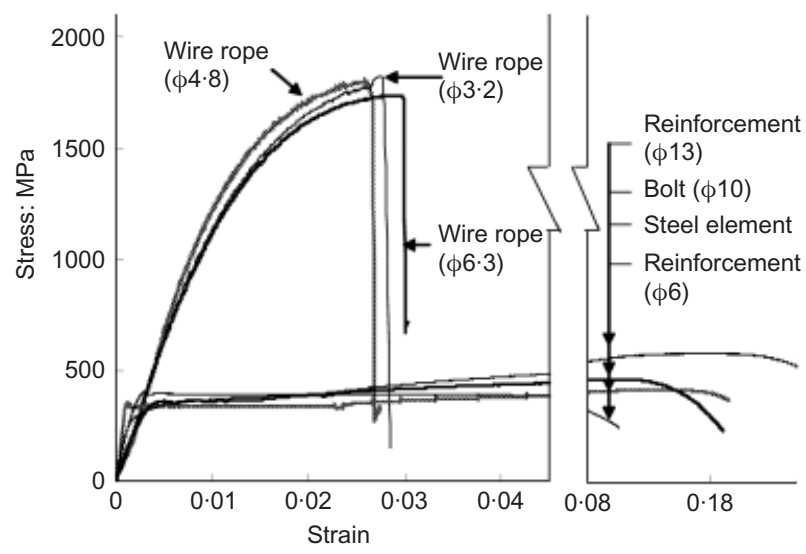

Fig. 4. Stress-strain relationships of metallic materials

Table 2. Mechanical properties of metallic material

\begin{tabular}{|c|c|c|c|c|c|c|c|}
\hline Type & $t: \mathrm{mm}$ & Dia.: mm & $A_{\text {net }}: \mathrm{mm}^{2}$ & $f_{\mathrm{y}}: \mathrm{MPa}$ & $\varepsilon_{\mathrm{y}}$ & $f_{\mathrm{u}}: \mathrm{MPa}$ & $E_{\mathrm{s}}: \mathrm{GPa}$ \\
\hline Steel element & $2 \cdot 1$ & - & - & 335 & $0 \cdot 00158$ & 414 & $211 \cdot 5$ \\
\hline Eye-bolt & - & 10 & $78 \cdot 50$ & 355 & $0 \cdot 00187$ & 465 & $190 \cdot 0$ \\
\hline \multirow[t]{2}{*}{ Reinforcement } & - & 6 & $28 \cdot 27$ & $352^{*}$ & 0.00370 & 394 & $205 \cdot 6$ \\
\hline & - & 13 & $127 \cdot 00$ & 396 & $0 \cdot 00198$ & 581 & $199 \cdot 9$ \\
\hline \multirow[t]{3}{*}{ Wire rope } & - & $3 \cdot 2$ & 5.09 & - & - & 1812 & $119 \cdot 4$ \\
\hline & - & $4 \cdot 8$ & $10 \cdot 83$ & - & - & 1795 & $122 \cdot 0$ \\
\hline & - & $6 \cdot 3$ & $18 \cdot 60$ & - & - & 1738 & $111 \cdot 6$ \\
\hline
\end{tabular}

$t=$ thickness of steel element, $A_{\text {net }}=$ net area, $f_{\mathrm{y}}=$ yield strength, $\varepsilon_{\mathrm{y}}=$ yield strain, $f_{\mathrm{u}}=$ tensile strength and $E_{\mathrm{s}}=$ elastic modulus.

* The yield strength of $6 \mathrm{~mm}$ diameter reinforcement was obtained by the $0 \cdot 2 \%$ offset method. 
ships and mechanical properties of reinforcement, wire rope, steel element and eye-bolt used in the present study, respectively. The wire rope used consists of six strands laid helically over a central core, which consists of a smaller independent wire rope core. The wire rope does not exhibit a yield plateau as shown in Fig. 4. Raoof and Kraincanic ${ }^{13}$ pointed out that the effective elastic modulus of wire ropes is mainly dependent on the lay angle, number of wires and strands and friction coefficient in the contact line of each wire. The elastic modulus of wire ropes used in column strengthening was $55-60 \%$ of the elastic modulus of steel of $200 \mathrm{GPa}$ (see Fig. 4), agreeing with the range recommended by Raoof and Kraincanic. ${ }^{13}$

\section{Instrumentation and test set-up}

All columns were loaded concentrically using a $3000 \mathrm{kN}$ capacity universal testing machine with a displacement rate of $0 \cdot 15 \mathrm{~mm} / \mathrm{min}$. In the test region of all columns, displacement was recorded by $50 \mathrm{~mm}$ capacity linear variable differential transducers (LVDTs) mounted along the four corners of the columns, as shown in Fig. 5, and strains of T- and L-shaped steel elements and longitudinal bars were measured by $5 \mathrm{~mm}$ electrical resistance strain (ERS) gauges bonded at different locations, as shown in Fig. 2. Plaster was spread between the column surface and loading plate to achieve uniform distribution of the applied load. A spherical hinge was also set between the testing machine head and columns to trace concentric axial load in large deformation. The tests were terminated when either a wire rope was fractured or the load suddenly

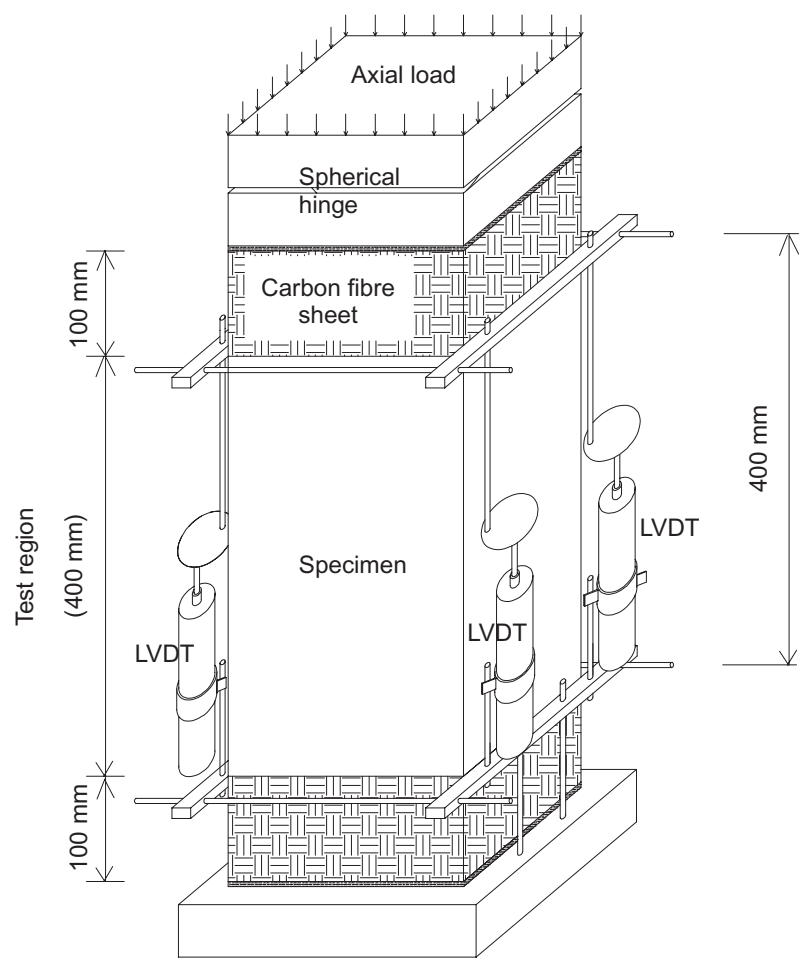

Fig. 5. Test set-up and instrumentation at test region dropped. All test data were captured by a data logger and automatically stored.

\section{Test results and discussions}

\section{General behaviour}

Figure 6 shows the characteristic behaviour of columns strengthened with wire rope units and steel elements. The load at first crack, $P_{\text {cr }}$, and ultimate load capacity, $P_{\mathrm{n}}$, are also presented in Table 3 . Initial cracks in cover mortar commonly occurred at $80-90 \%$ of maximum strength of the column along the steel elements as shown in Fig. 6(a) and Table 3. At average longitudinal strain values of $0 \cdot 002-0 \cdot 0025$, the separation of the cover mortar from the core concrete appeared owing to lateral tensile strains created as a result of the Poisson effect, as shown in Fig. 6(b), and then columns reached their maximum strength. Beyond this stage, the load-carrying capacity of core concrete is primarily a function of confinement provided by wire rope units and steel elements. Owing to buckling of longitudinal reinforcement and steel elements as shown in Fig. 6(c), the load-carrying capacity of core concrete suddenly dropped, and then wire ropes were ruptured, as depicted in Fig. 6(d).

Axial strains in different columns against applied axial load are shown in Fig. 7. The axial strains were calculated as the ratio of average displacement obtained from the four LVDTs attached to the corners of columns tested to the gauge length of $400 \mathrm{~mm}$. The test results of unstrengthened column $\mathrm{C} 1$ are also given in Fig. 7(a). The initial stiffness of strengthened columns was slightly higher than that of the corresponding unstrengthened column $\mathrm{C} 1$ owing to the load-carrying effect of steel elements. For columns having the same volume ratio of wire ropes, the maximum strength was nearly independent of the diameter and spacing of wire ropes, and higher ductility developed in columns with smaller diameter and closer spacing of wire ropes. However, the smaller the diameter of wire ropes, the earlier the rupture of wire ropes, leading to a sudden drop of axial load resistance of columns, as shown in Fig. 7(a). The volume ratio $\rho_{\mathrm{w}}$ of wire ropes had a significant effect on the maximum strength and ductility of strengthened columns as shown in Fig. 7(b), while the initial prestressing force applied to wire ropes had little influence on column behaviour. However, the higher the initial prestress in wire ropes, the earlier the rupture of wire ropes as shown in Fig. 7(c). At the same volume ratio $\rho_{\mathrm{w}}$ of wire ropes, the maximum strength of columns was nearly independent on the configuration of wire ropes, but higher ductility was exhibited by columns strengthened with rectangular spiral-type wire ropes than by columns strengthened with hoop-type wire ropes until rupture of wire ropes, as shown in Fig. 7(d). 


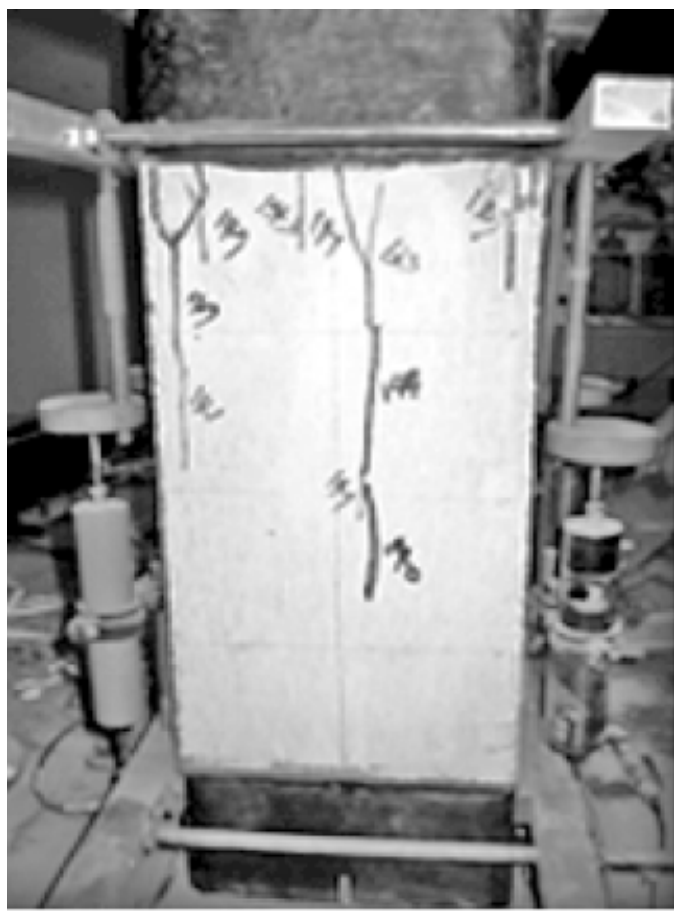

(a)

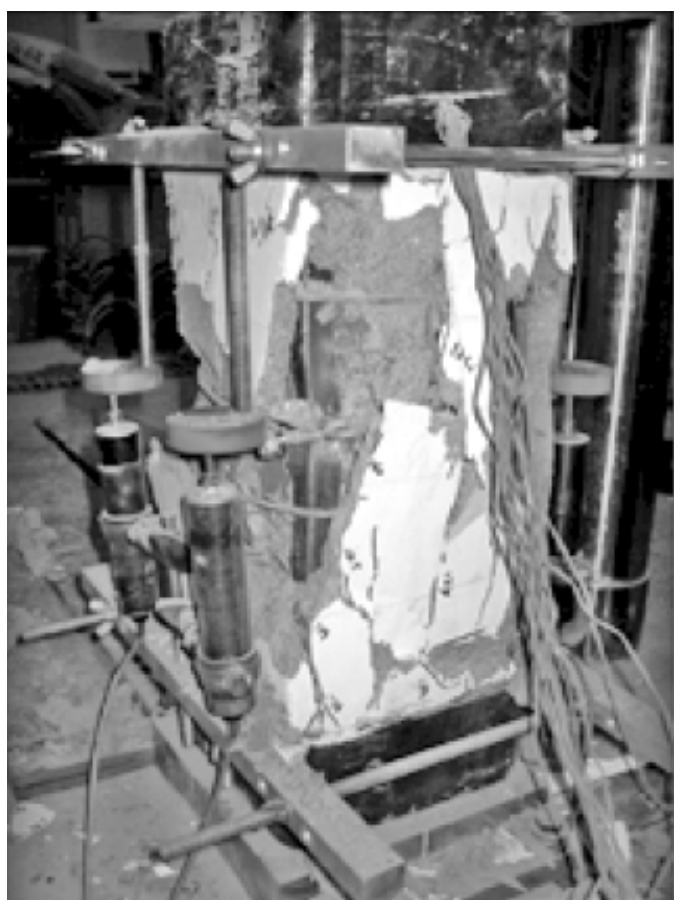

(c)

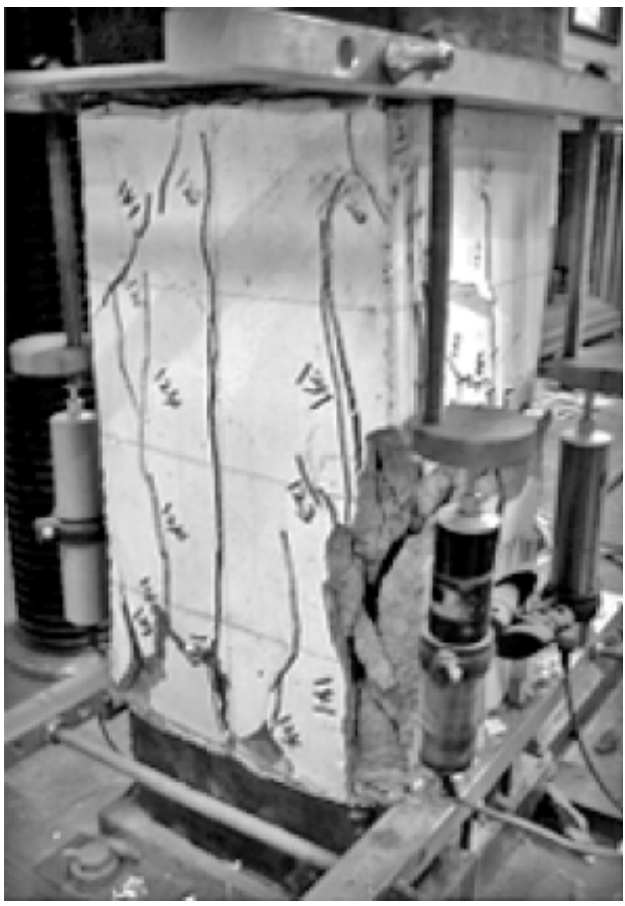

(b)

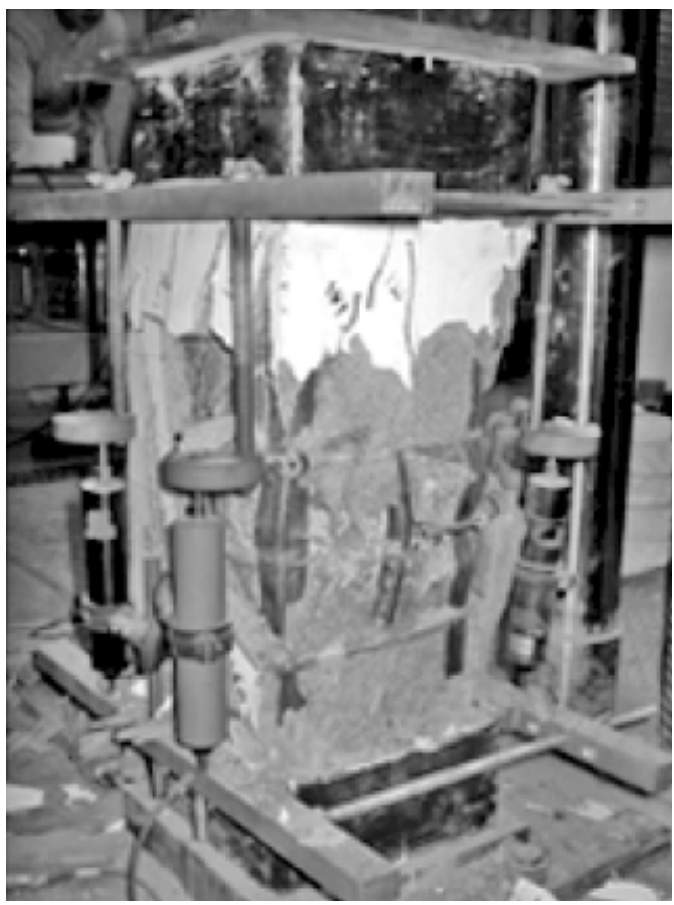

(d)

Fig. 6. Characteristic behaviour of column C2 during test: (a) crack propagation at cover mortar; (b) spalling of cover mortar; (c) buckling of longitudinal reinforcement and steel element; (d) rupture of wire rope

\section{Load-carrying capacity of core concrete}

Figure 8 shows the average strains in longitudinal reinforcement and steel elements, measured using ERS gauges given in Fig. 2, against applied axial load for the specimen $\mathrm{C} 2$. Up to the occurrence of initial cracking in cover mortar, all longitudinal reinforcement and steel elements practically behaved in a similar manner.
With the occurrence of initial cracking, the strain increase rate of steel elements was relieved compared with longitudinal reinforcement. After spalling of the cover mortar, strains in steel elements abruptly dropped while those of internal longitudinal reinforcement continuously increased. The load-carrying capacity of steel elements would be dependent on the spalling of cover

Magazine of Concrete Research, 2007, 59, No. 8 
Table 3. Details of test results

\begin{tabular}{|c|c|c|c|c|c|c|c|c|c|c|}
\hline \multirow[t]{2}{*}{ Specimen } & \multicolumn{10}{|c|}{ Test results } \\
\hline & $P_{\mathrm{cr}}: \mathrm{kN}$ & $P_{\mathrm{n}}: \mathrm{kN}$ & $\varepsilon_{85}$ & $\left(f_{\mathrm{cc}}\right)_{\mathrm{U}}: \mathrm{MPa}$ & $\left(f_{\mathrm{cc}}\right)_{\mathrm{L}}: \mathrm{MPa}$ & $\left(K_{\mathrm{s}}\right)_{\mathrm{U}}$ & $\left(K_{\mathrm{s}}\right)_{\mathrm{L}}$ & $\mu$ & $\frac{P_{\mathrm{cr}}}{P_{\mathrm{n}}}$ & $\frac{\left(P_{\mathrm{n}}\right)}{\left(P_{\mathrm{n}}\right)_{\mathrm{Cl}}}$ \\
\hline $\mathrm{C} 1$ & 1180 & $1289 \cdot 4$ & 0.0058 & $21 \cdot 1$ & $21 \cdot 1$ & - & - & 1.46 & 0.92 & 1.00 \\
\hline $\mathrm{C} 2$ & 1134 & $1428 \cdot 6$ & $0 \cdot 0124$ & $31 \cdot 2$ & $23 \cdot 0$ & $1 \cdot 62$ & $1 \cdot 19$ & $3 \cdot 11$ & 0.79 & $1 \cdot 11$ \\
\hline $\mathrm{C} 3$ & 1082 & $1494 \cdot 6$ & $0 \cdot 0169$ & $36 \cdot 9$ & $28 \cdot 6$ & 1.91 & $1 \cdot 48$ & $4 \cdot 23$ & 0.72 & $1 \cdot 16$ \\
\hline $\mathrm{C} 4$ & 1247 & $1479 \cdot 9$ & $0 \cdot 0077$ & $30 \cdot 1$ & $21 \cdot 9$ & $1 \cdot 56$ & $1 \cdot 13$ & 1.92 & 0.84 & $1 \cdot 15$ \\
\hline C5 & 1218 & $1569 \cdot 8$ & $0 \cdot 0182$ & $37 \cdot 3$ & $30 \cdot 3$ & 1.93 & 1.57 & $4 \cdot 56$ & 0.78 & $1 \cdot 22$ \\
\hline C6 & 1214 & $1367 \cdot 5$ & $0 \cdot 0110$ & $24 \cdot 5$ & $20 \cdot 3$ & $1 \cdot 27$ & $1 \cdot 05$ & $2 \cdot 75$ & 0.89 & $1 \cdot 06$ \\
\hline C7 & 1016 & $1343 \cdot 8$ & $0 \cdot 0082$ & $21 \cdot 2$ & $18 \cdot 7$ & $1 \cdot 10$ & 0.97 & $2 \cdot 04$ & $0 \cdot 76$ & $1 \cdot 04$ \\
\hline $\mathrm{C} 8$ & 1121 & $1464 \cdot 4$ & $0 \cdot 0162$ & $31 \cdot 0$ & $25 \cdot 5$ & $1 \cdot 60$ & $1 \cdot 32$ & $4 \cdot 13$ & $0 \cdot 77$ & $1 \cdot 14$ \\
\hline C9 & 1205 & $1481 \cdot 5$ & $0 \cdot 0127$ & $31 \cdot 3$ & $27 \cdot 1$ & 1.62 & $1 \cdot 40$ & $3 \cdot 18$ & $0 \cdot 81$ & $1 \cdot 15$ \\
\hline $\mathrm{C} 10$ & 1238 & $1398 \cdot 0$ & $0 \cdot 0123$ & $30 \cdot 7$ & $22 \cdot 4$ & 1.59 & $1 \cdot 16$ & 3.07 & $0 \cdot 89$ & 1.08 \\
\hline C11 & 1018 & $1342 \cdot 2$ & $0 \cdot 0090$ & $21 \cdot 8$ & $18 \cdot 0$ & $1 \cdot 13$ & 0.93 & $2 \cdot 25$ & $0 \cdot 76$ & $1 \cdot 04$ \\
\hline
\end{tabular}

$P_{\text {cr }}=$ load at first crack, $P_{\mathrm{n}}=$ ultimate load capacity, $\varepsilon_{85}=$ strain value of column corresponding to 0.85 times the ultimate load capacity in declined curve, $f_{\mathrm{cc}}=$ ultimate stress of core concrete, $\left(K_{\mathrm{s}}\right)_{\mathrm{U}}$ and $\left(K_{\mathrm{s}}\right)_{\mathrm{L}}=$ upper and lower bounds, respectively, for strength gain factor, and $\mu=$ ductility ratio.

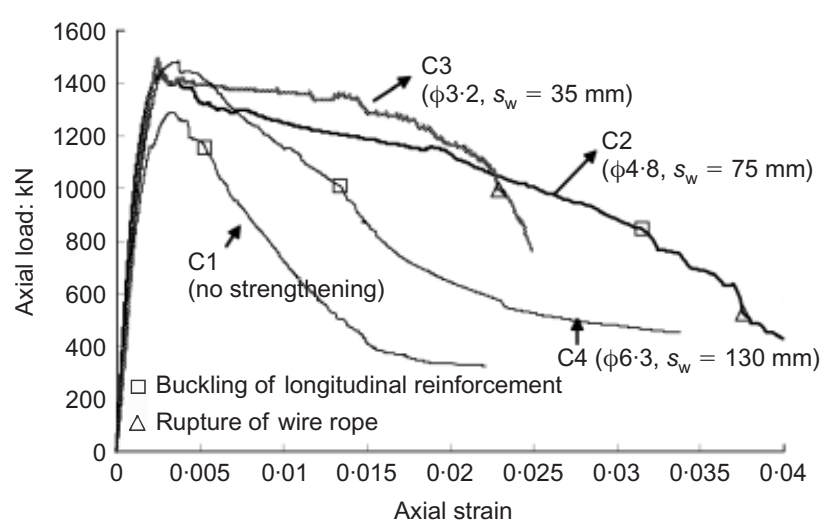

(a)

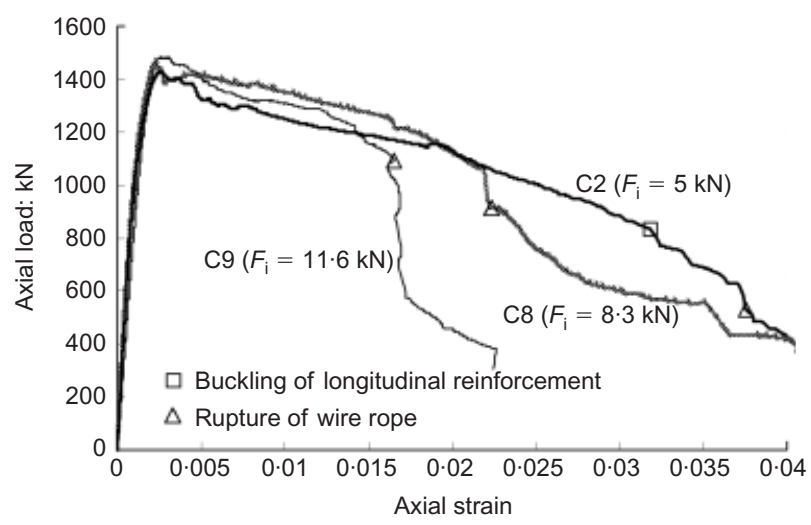

(c)

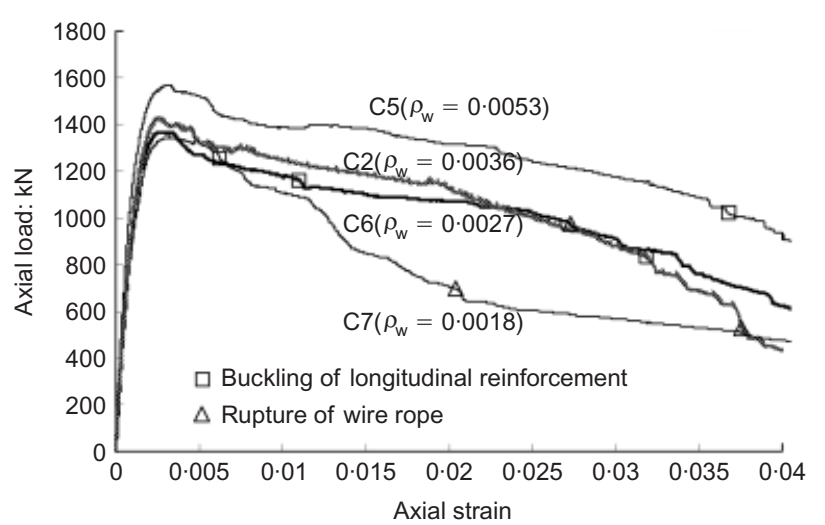

(b)

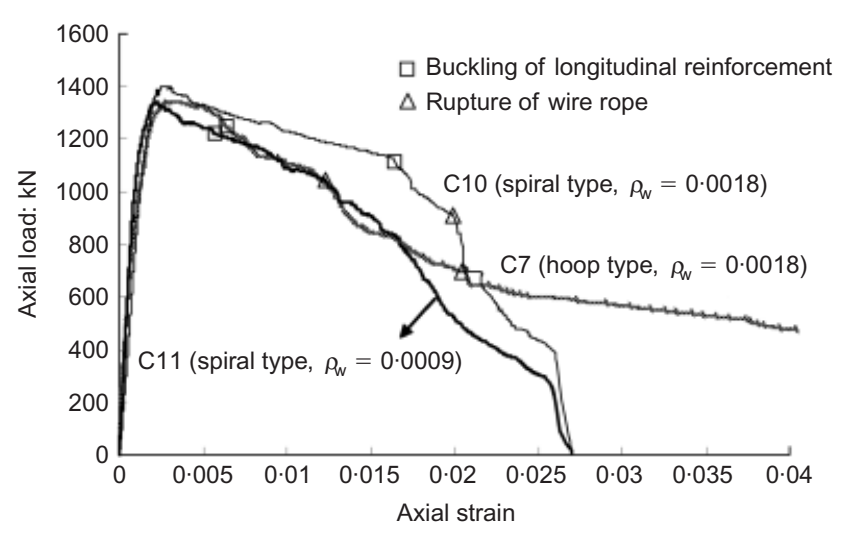

(d)

Fig. 7. Axial strain against applied axial load: (a) diameter and spacing of wire ropes ( $\left.\rho_{\mathrm{w}}=0.0034\right)$ including C1; (b) spacing of wire ropes (volume ratio of wire ropes); (c) initial tensile force of wire ropes (prestress of wire rope); (d) arrangement type and spacing of wire ropes

mortar as steel elements were placed only within the test region, as shown in Fig. 2. Axial strains in all longitudinal reinforcement and steel elements at column failure were beyond their yield strains.

Figure 9 shows the load-carrying capacities of Magazine of Concrete Research, 2007, 59, No. 8 cover mortar $P_{\mathrm{cm}}$, steel elements $P_{\mathrm{sp}}$, longitudinal reinforcement $P_{\mathrm{s}}$ and core concrete $P_{\mathrm{cc}}$ for specimen C2. For the calculation of load-carrying capacity of each element, the stress-strain relationships for cover mortar, longitudinal reinforcement and steel elements, 


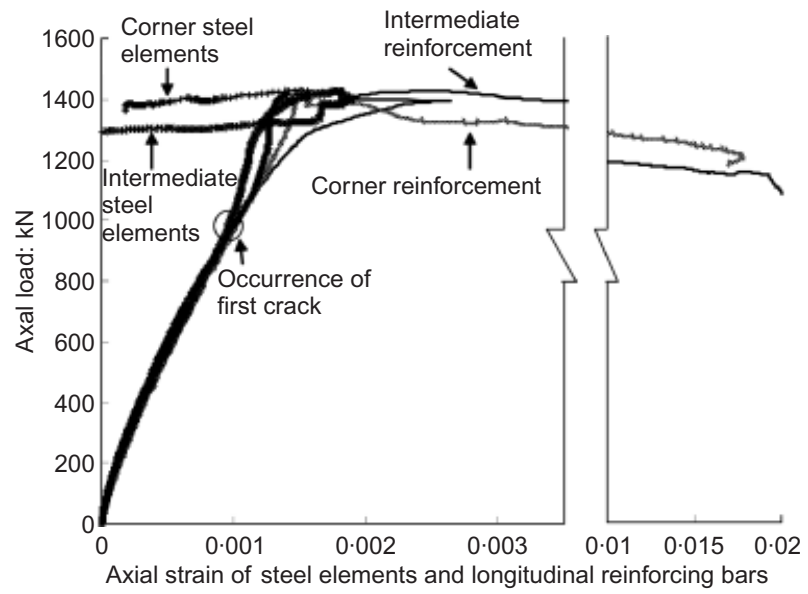

Fig. 8. Axial strains in reinforcement and steel elements against axial load for column $\mathrm{C} 2$

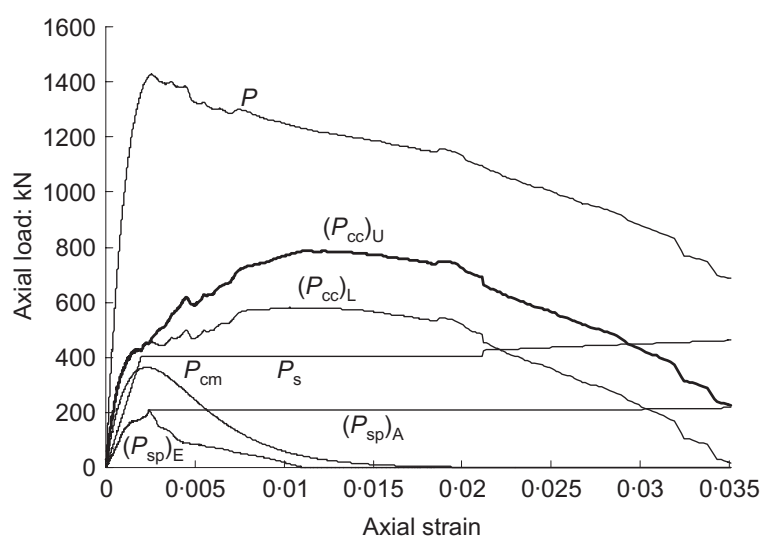

Fig. 9. Load transfer contribution of core concrete

as presented in Figs 3 and 4, are employed. As partial spalling of cover mortar of strengthened columns as shown in Fig. 6(b) occurred for most columns tested, strains and stresses in different steel elements were not the same. Steel elements close to the spalled cover mortar experienced stress softening, whereas those far away from the spalled cover mortar exhibited a yielding plateau. Therefore, the load-carrying capacity of steel elements is represented in Fig. 9 by two different values: one value, $\left(P_{\mathrm{sp}}\right)_{\mathrm{E}}$, is calculated according to the average strain measured by ERS gauges while the other, $\left(P_{\mathrm{sp}}\right)_{\mathrm{A}}$, corresponds to the yield strength of steel elements. The actual contribution of steel elements to the load-carrying capacity of columns would be somewhere between these two limits. The load-carrying capacity $P_{\mathrm{cc}}$ of core concrete at each axial strain increment is obtained from the difference between the total applied load and load-carrying capacities of other elements including cover mortar, longitudinal reinforcement and steel elements. ${ }^{2,4,6}$ According to the two different values of the load-carrying capacity of steel elements, the upper $\left(P_{\mathrm{cc}}\right)_{\mathrm{U}}$ and lower $\left(P_{\mathrm{cc}}\right)_{\mathrm{L}}$ bounds for load-carrying capacity of core concrete can also be calculated as represented in Fig. 9, indicating that the load-carrying capacity of core concrete confined by the strengthening technique would be between these two bounds. The load-carrying capacity of core concrete confined by wire rope units and steel elements increased even after spalling of the cover mortar and, beyond peak strength of core concrete, a slower decreasing rate is shown compared with that of concrete obtained from the cylinder test shown in Fig. 3. This indicates that the confinement effect provided by wire rope units and steel elements contributes to the increase of strength and ductility of concrete, similar to the case of tied columns confined by internal hoop. ${ }^{1-7}$

\section{Strength gain factor and ductility ratio}

The influence of lateral reinforcement on the behaviour of columns subjected to axial loads can be generally evaluated from a strength gain factor $K_{\mathrm{s}}$ of confined concrete and a ductility ratio $\mu$. The strength gain factor ${ }^{1-7,10}$ and ductility ratio ${ }^{3,4}$ of columns tested can be defined as follows

$$
\begin{aligned}
K_{\mathrm{s}} & =\frac{f_{\mathrm{cc}}}{0.85 f_{\mathrm{c}}^{\prime}} \\
\mu & =\frac{\varepsilon_{85 \%}}{0.004}
\end{aligned}
$$

where $f_{\mathrm{cc}}$ is the maximum stress of confined core concrete, which is the ratio of the load-carrying capacity of the core concrete as shown in Fig. 9 divided by the area of the core, and $\varepsilon_{85 \%}$ is the strain value of strengthened columns corresponding to $85 \%$ of the maximum strength. The upper $\left(K_{\mathrm{S}}\right)_{\mathrm{U}}$ and lower $\left(K_{\mathrm{S}}\right)_{\mathrm{L}}$ bounds for the strength gain factor can be obtained from those of the load-carrying capacity of core concrete as given in Table 3 . The measured ductility ratio obtained from equation (3) for different specimens is also presented in Table 3. Table 4 gives the empirical models proposed by Kent and Park, ${ }^{2}$ Saatcioglu and Razvi $^{4}$ and Sheikh and Uzumeri ${ }^{7}$ for the strength gain factor, which are based on test results of tied columns confined by internal hoops. The strength gain factor of confined concrete is generally affected by index $\left(\rho_{\mathrm{h}} f_{\mathrm{yh}}\right) / f_{\mathrm{c}}^{\prime}$ and configuration of lateral reinforcement as shown in Table 4, where $\rho_{\mathrm{h}}$ and $f_{\mathrm{yh}}$ are volume ratio and yield strength of lateral reinforcement, respectively.

The comparison between the strength gain factor as obtained from equation (2) and that predicted by the empirical models given in Table 4 is presented in Table 5. The strength gain factor and ductility ratio increased with the increase of volume ratio of wire ropes. For the same volume ratio of wire ropes, the smaller the diameter and the closer the spacing of wire ropes, the higher the strength gain factor and ductility ratio, similar to the case of tied columns. ${ }^{10}$ The prestress applied to wire ropes had little influence on the strength gain factor but the ductility ratio decreased with the increase of the prestress in wire ropes as earlier rupture of wire ropes occurred. The measured upper bound for strength gain factor of strengthened core concrete except speci-

Magazine of Concrete Research, 2007, 59, No. 8 
Table 4. Summary of empirical formulae for strength gain factor

\begin{tabular}{|c|c|}
\hline Researcher & Strength gain factor \\
\hline Kent and Park ${ }^{2}$ & $K_{\mathrm{s}}=1+\frac{\rho_{\mathrm{h}} f_{\mathrm{yh}}}{f_{\mathrm{c}}^{\prime}}$ \\
\hline Saatcioglu and Razvi ${ }^{4}$ & $\begin{array}{l}K_{\mathrm{s}}=1+\frac{\rho_{\mathrm{h}} f_{\mathrm{le}}}{f_{\mathrm{c}}^{\prime}} \\
\text { where } \\
f_{\mathrm{le}}=k_{2} f_{1}\end{array}$ \\
\hline & $\begin{array}{l}k_{2}=0 \cdot 26 \sqrt{\frac{D_{\mathrm{c}}}{s_{\mathrm{h}}}-\frac{D_{\mathrm{c}}}{C} \frac{1}{f_{1}}} \leqslant 1 \cdot 0 \\
f_{1}=\frac{\sum A_{\mathrm{h}} f_{\mathrm{yh}} \sin \alpha}{D_{\mathrm{c}} s_{\mathrm{h}}}\end{array}$ \\
\hline Sheikh and Uzumeri ${ }^{7}$ & $\begin{array}{l}K_{\mathrm{s}}=1+\frac{D_{\mathrm{c}}^{2}}{140 P_{\mathrm{occ}}}\left[\left(1-\frac{n C^{2}}{5 \cdot 5 D_{\mathrm{c}}^{2}}\right)\left(1-\frac{s_{\mathrm{h}}}{2 D_{\mathrm{c}}}\right)^{2}\right] \sqrt{\rho_{\mathrm{h}} f_{\mathrm{yh}}} \\
\text { where } P_{\mathrm{occ}}=0 \cdot 85 f_{\mathrm{c}}^{\prime}\left(A_{\mathrm{cc}}-A_{\mathrm{s}}\right)(\text { in } \mathrm{kN})\end{array}$ \\
\hline
\end{tabular}

$\rho_{\mathrm{h}}=$ volume ratio of lateral reinforcement, $f_{\mathrm{yh}}=$ yield strength of lateral reinforcement, $f_{\mathrm{c}}^{\prime}=$ compressive strength of concrete, $D_{\mathrm{c}}=$ core width, $s_{\mathrm{h}}=$ spacing of lateral reinforcement, $C=$ distance between longitudinal bars confined by lateral reinforcement, $A_{\mathrm{h}}=$ area of lateral reinforcement, $\alpha=$ angle between lateral reinforcement and core width and is equal to $90^{\circ}$ if the rectangular hoop is arranged, $n=$ number of longitudinal reinforcement, $A_{\mathrm{cc}}=$ area of core concrete, and $A_{\mathrm{s}}=$ area of longitudinal reinforcement.

Table 5. Comparisons of test results and predictions

\begin{tabular}{|c|c|c|c|c|c|c|c|c|c|c|c|c|c|c|}
\hline \multirow[t]{3}{*}{ Specimen } & \multicolumn{3}{|c|}{ Test results } & \multicolumn{4}{|c|}{ Predictions } & \multicolumn{7}{|c|}{ Tests/predictions } \\
\hline & \multirow[t]{2}{*}{$P_{\mathrm{n}}: \mathrm{kN}$} & \multirow[t]{2}{*}{$\left(K_{\mathrm{s}}\right)_{\mathrm{U}}$} & \multirow[t]{2}{*}{$\left(K_{\mathrm{s}}\right)_{\mathrm{L}}$} & \multirow[t]{2}{*}{$P_{\mathrm{n}}$} & \multicolumn{3}{|c|}{$K_{\mathrm{s}}^{*}$} & \multirow[t]{2}{*}{$P_{\mathrm{n}}$} & \multicolumn{3}{|c|}{$\left(K_{\mathrm{s}}\right)_{\mathrm{U}}$} & \multicolumn{3}{|c|}{$\left(K_{\mathrm{s}}\right)_{\mathrm{L}}$} \\
\hline & & & & & $\mathrm{K}-\mathrm{P}$ & $\mathrm{S}-\mathrm{R}$ & $\mathrm{S}-\mathrm{U}$ & & $\mathrm{K}-\mathrm{P}$ & $\mathrm{S}-\mathrm{R}$ & $\mathrm{S}-\mathrm{U}$ & $\mathrm{K}-\mathrm{P}$ & $\mathrm{S}-\mathrm{R}$ & $\mathrm{S}-\mathrm{U}$ \\
\hline $\mathrm{C} 1$ & $1289 \cdot 4$ & - & - & $1214 \cdot 8$ & - & - & - & $1 \cdot 061$ & - & - & - & - & - & - \\
\hline $\mathrm{C} 2$ & $1428 \cdot 6$ & $1 \cdot 62$ & $1 \cdot 19$ & $1410 \cdot 9$ & $1 \cdot 21$ & $1 \cdot 19$ & $1 \cdot 37$ & $1 \cdot 013$ & $1 \cdot 339$ & $1 \cdot 361$ & $1 \cdot 182$ & 0.983 & $1 \cdot 000$ & $0 \cdot 869$ \\
\hline $\mathrm{C} 3$ & $1494 \cdot 6$ & 1.91 & $1 \cdot 48$ & $1410 \cdot 9$ & $1 \cdot 13$ & $1 \cdot 30$ & $1 \cdot 39$ & $1 \cdot 059$ & 1.690 & 1.469 & $1 \cdot 374$ & $1 \cdot 310$ & $1 \cdot 138$ & $1 \cdot 065$ \\
\hline $\mathrm{C} 4$ & $1479 \cdot 9$ & $1 \cdot 56$ & $1 \cdot 13$ & $1410 \cdot 9$ & $1 \cdot 23$ & $1 \cdot 13$ & $1 \cdot 23$ & $1 \cdot 049$ & $1 \cdot 268$ & $1 \cdot 381$ & $1 \cdot 268$ & $0 \cdot 919$ & $1 \cdot 000$ & 0.919 \\
\hline $\mathrm{C} 5$ & $1569 \cdot 8$ & 1.93 & $1 \cdot 57$ & $1410 \cdot 9$ & $1 \cdot 31$ & $1 \cdot 32$ & $1 \cdot 55$ & $1 \cdot 113$ & $1 \cdot 473$ & $1 \cdot 462$ & $1 \cdot 245$ & $1 \cdot 198$ & $1 \cdot 189$ & $1 \cdot 013$ \\
\hline C6 & $1367 \cdot 5$ & $1 \cdot 27$ & $1 \cdot 05$ & $1410 \cdot 9$ & $1 \cdot 16$ & $1 \cdot 13$ & $1 \cdot 26$ & 0.969 & 1.095 & $1 \cdot 124$ & $1 \cdot 008$ & 0.905 & 0.929 & 0.833 \\
\hline $\mathrm{C} 7$ & $1343 \cdot 8$ & $1 \cdot 10$ & 0.97 & $1410 \cdot 9$ & $1 \cdot 10$ & 1.08 & $1 \cdot 13$ & 0.952 & 1.000 & 1.019 & 0.973 & $0 \cdot 882$ & 0.898 & 0.858 \\
\hline $\mathrm{C} 8$ & $1464 \cdot 4$ & $1 \cdot 60$ & $1 \cdot 32$ & $1410 \cdot 9$ & $1 \cdot 11$ & $1 \cdot 15$ & $1 \cdot 27$ & $1 \cdot 038$ & $1 \cdot 441$ & $1 \cdot 391$ & $1 \cdot 260$ & $1 \cdot 189$ & $1 \cdot 148$ & 1.039 \\
\hline $\mathrm{C} 9$ & $1481 \cdot 5$ & $1 \cdot 62$ & $1 \cdot 40$ & $1410 \cdot 9$ & $1 \cdot 16$ & $1 \cdot 17$ & $1 \cdot 33$ & $1 \cdot 050$ & $1 \cdot 397$ & $1 \cdot 385$ & $1 \cdot 218$ & $1 \cdot 207$ & $1 \cdot 197$ & $1 \cdot 053$ \\
\hline $\mathrm{C} 10$ & $1398 \cdot 0$ & 1.59 & $1 \cdot 16$ & $1410 \cdot 9$ & 1.07 & $1 \cdot 12$ & $1 \cdot 22$ & 0.991 & $1 \cdot 486$ & $1 \cdot 420$ & $1 \cdot 303$ & $1 \cdot 084$ & 1.036 & 0.951 \\
\hline C11 & $1342 \cdot 2$ & $1 \cdot 13$ & 0.93 & $1410 \cdot 9$ & 1.03 & $1 \cdot 05$ & 1.08 & 0.951 & 1.097 & 1.076 & $1 \cdot 046$ & 0.903 & 0.886 & $0 \cdot 861$ \\
\hline
\end{tabular}

* Kent-Park's, Saatcioglu and Razvi's and Sheikh and Uzumeri's abbreviations are represented as K-P, S-R and S-U, respectively.

mens C7 and C11 having wire rope spacing larger than $D_{\mathrm{c}} / 2$ was more than 1.2 times higher than predictions obtained from the models of Kent and Park, ${ }^{2}$ Saatcioglu and Razvi ${ }^{4}$ and Sheikh and Uzumeri's, ${ }^{7}$ where $D_{\mathrm{c}}$ is the core width. In addition, even the lower bound for the measured strength gain factor is higher than predictions for most columns.

Figure 10 shows the variation of the strength gain factor and ductility ratio against the lateral reinforcement index, $\left(\rho_{\mathrm{w}} f_{\mathrm{sw}}\right) / f_{\mathrm{c}}^{\prime}$, for columns strengthened with wire rope units and steel elements, and $\left(\rho_{\mathrm{h}} f_{\mathrm{yh}}\right) / f_{\mathrm{c}}^{\prime}$ for tied columns confined by internal hoops, where $f_{s w}$ is the wire rope stress developed at peak stress of core concrete, therefore, it can be assumed to be $f_{\mathrm{pu}}-f_{\mathrm{i}}$, where $f_{\mathrm{pu}}$ and $f_{\mathrm{i}}$ are tensile strength and initial tensile stress in the wire ropes, respectively. On the same figures, test results of tied columns having similar geometrical dimensions and reinforcement arrangement carried out by Chung et al. ${ }^{10}$ are also plotted. The strength gain factor and ductility ratio of columns slightly increased with the increase of the lateral reinforcement index. A higher increasing rate, larger 


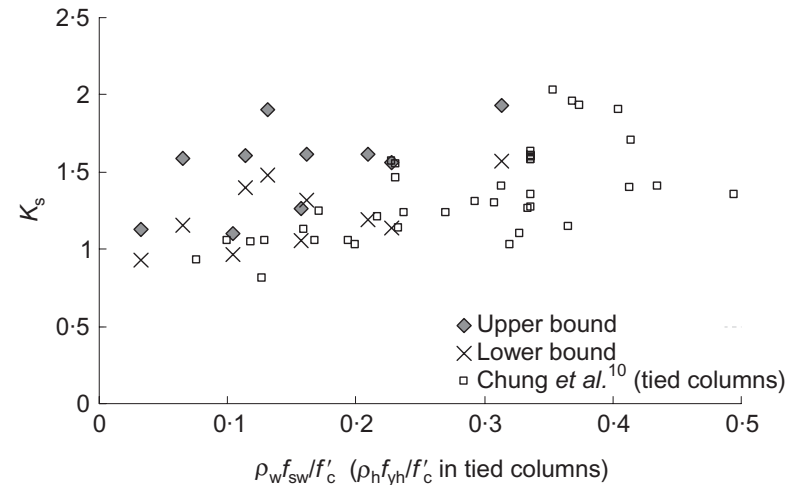

(a)

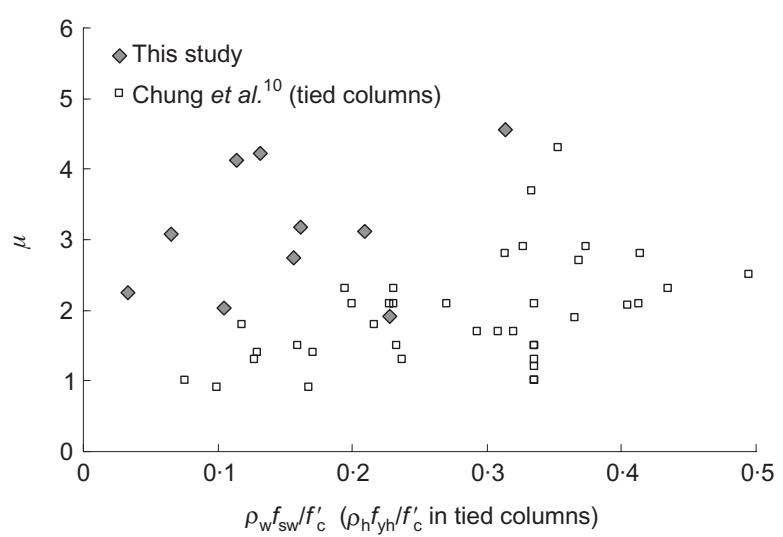

(b)

Fig. 10. Effect of lateral reinforcement index on behaviour of confined concrete: (a) strength gain factor $K_{s}$; (b) ductility ratio $\mu$

strength gain factor - even for lower bound - and ductility ratio for the same lateral reinforcement index developed in the strengthened columns-except for specimens $\mathrm{C} 7$ and $\mathrm{C} 11$, which had wire rope spacings larger than $D_{\mathrm{c}} / 2$ - than in the tied columns confined by internal hoops. From Fig. 10, it can be suggested that the developed strengthening method is superior to the internal hoop for concrete confinement, and the maximum spacing of wire rope units to provide effective confinement is below $D_{\mathrm{c}} / 2$.

\section{Axial load capacity predictions}

The axial loads applied to concrete columns strengthened with wire rope units and steel elements are transferred by core concrete, longitudinal reinforcement, steel elements and cover mortar as shown in Fig. 9. Therefore, the axial load capacity of strengthened columns can be expressed as follows

$$
\begin{aligned}
P_{\mathrm{n}}= & 0.85 f_{\mathrm{c}}^{\prime}\left(A_{\mathrm{cc}}-A_{\mathrm{s}}\right)+0 \cdot 85 f_{\mathrm{m}}^{\prime}\left(A_{\mathrm{co}}-A_{\mathrm{sp}}\right)+A_{s} f_{\mathrm{y}} \\
& +A_{\mathrm{sp}} f_{\mathrm{yp}}
\end{aligned}
$$

where $A_{\mathrm{cc}}$ and $A_{\mathrm{co}}$ are the area of core concrete and cover mortar, respectively; $A_{\mathrm{s}}$ and $A_{\mathrm{sp}}$ are the area of longitudinal reinforcement and steel elements, respectively; and $f_{\mathrm{y}}$ and $f_{\mathrm{yp}}$ are the yield strength of longitudinal reinforcement and steel elements, respectively.
Equation (4) is a modified version of the ACI 318-05 ${ }^{11}$ formula to estimate the axial capacity of short reinforced concrete columns.

The ratio of the maximum load capacity of strengthened columns to that of unstrengthened column $\mathrm{C}$ 1, and comparisons between measured axial load capacity and prediction obtained from equation (4) above are given in Tables 3 and 5, and Fig. 11. The predicted load capacity of unstrengthened column $\mathrm{C} 1$ is calculated from the equation proposed by ACI 318-05. The axial load capacity of strengthened columns was higher than that of the unstrengthened column by $5-20 \%$. The axial load capacity of strengthened columns is reasonably predicted using the modified equation of ACI 31805, although the test results for columns C6, C7 and C11 having wire rope spacing above $D_{\mathrm{c}} / 2$ are lower than the predictions by $3-5 \%$.

\section{Conclusions}

Eleven reinforced concrete columns strengthened using developed wire rope units and steel elements were tested under concentric axial load. The following conclusions may be drawn.

(a) The initial stiffness of strengthened columns was slightly higher than that of the corresponding unstrengthened column.

(b) The load-carrying capacity of core concrete strengthened with wire rope units and steel elements increased even after spalling of the cover mortar and, beyond peak strength of core concrete, a slower decreasing rate is shown compared with that of unstrengthened concrete.

(c) The strength gain factor and ductility ratio increased with the increase of volume ratio of wire ropes. The initial prestress applied to wire ropes had little influence on the strength gain factor but the ductility ratio decreased with the increase of the initial prestress of wire ropes as earlier rupture of wire ropes occurred.

(d) At the same volume ratio of wire ropes, the maximum strength of columns was almost independent of the configuration of wire ropes, but higher duc-

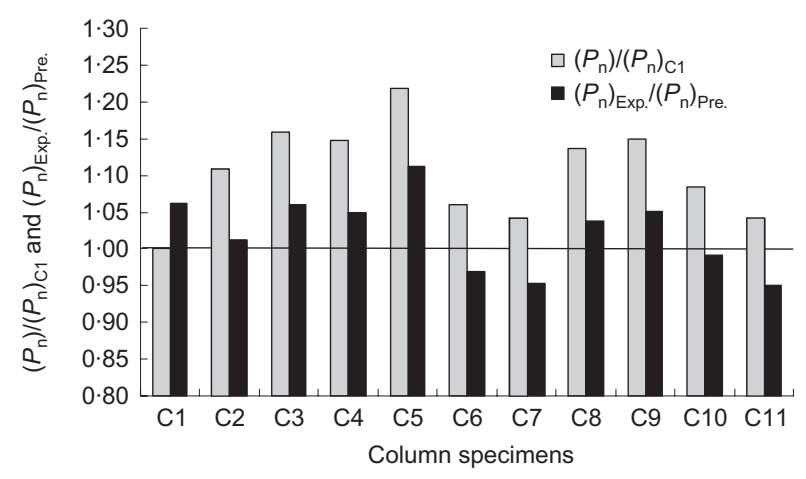

Fig. 11. Relative load capacity of different columns

Magazine of Concrete Research, 2007, 59, No. 8 
tility was observed in columns strengthened with rectangular spiral-type wire ropes than in columns strengthened with hoop-type wire ropes until the rupture of wire ropes.

(e) The measured upper and lower bounds for strength gain factor of strengthened core concrete except columns $\mathrm{C} 7$ and $\mathrm{C} 11$ having wire rope spacing larger than half the core width was higher than predictions obtained from empirical formulae of tied columns.

( $f$ ) The strength gain factor and ductility ratio of columns generally increased with increase of the lateral reinforcement index. Higher strength gain factor and ductility ratio was developed by strengthened columns than tied columns having the same lateral reinforcement index, except for columns strengthened with wire ropes spaced more than $0 \cdot 5$ times the core width.

( $g$ ) The axial load capacity of strengthened columns was higher than that of unstrengthened columns by $5-20 \%$, and could be reasonably predicted using a modified equation of ACI 318-05.

\section{Acknowledgement}

This work was supported by the Korea Research Foundation Grant funded by the Korean Government (MOEHRD). (KRF-2005-214-D00378)

\section{References}

1. Fafitis A. and Shah S. P. Predictions of ultimate behavior of confined columns subjected to large deformations. ACI Journal, 1985, 82, No. 3, 423-433.
2. Kent D. C. and Park R. Flexural members with confined concrete. Journal of the Structural Division, ASCE, 1971, 97, ST7, 1969-1990.

3. SaAtcioglu M. and Razvi S. R. Strength and ductility of confined concrete. Journal of the Structural Engineering, ASCE, 1992, 118, No. 6, 1590-1607.

4. Saatcioglu M. and Razvi S. R. Confinement model for highstrength concrete. Journal of the Structural Engineering, ASCE, 1999, 125, No. 3, 281-289.

5. SAKaI K. and Sheikh S. A. What do we know about confinement in reinforced concrete columns? ACI Journal, 1989, 86, No. 2, 192-207.

6. Sheikh S. A. and Uzumeri S. M. Strength and ductility of tied concrete columns. Journal of the Structural Division, 1980, 106, ST5, 1079-1101.

7. Sheikh S. A. and Uzumeri S. M. Analytical model for concrete confinement in tied columns. Journal of the Structural Division, ASCE, 1982, 108, ST12, 2703-2722.

8. Teng S., Kong F. K., Poh S. P., Gsuan L. W. and Tan K. H. Performance of strengthened concrete deep beams predamaged in shear. ACI Structural Journal, 1996, 93, No. 2, 159-171.

9. Kim S. Y., YANG K. H., Byun H. Y. and Ashour A. F. Tests of reinforced concrete beams strengthened with wire rope units. Engineering Structures, 2007, doi: 10.1016/j.engstruct.2006.12. 013.

10. Chung H. S., Yang K. H., LeE Y. H. and Eun H. C. Strength and ductility of laterally confined concrete columns. Canadian Structural Journal, 2002, 29, No. 6, 820-830.

11. American Concrete Institute. Building Code Requirements for Structural Concrete (ACI 318-05) and Commentary (ACI 318R-05). American Concrete Institute, Detroit, 2005. ACI Committee 318.

12. BICKFORD J. H. An Introduction to the Design and Behavior of Bolt Joints. Marcel Dekker, New York, 1990.

13. Raoof M. and Kraincanic I. Analysis of large diameter steel ropes. Journal of Engineering Mechanics, ASCE, 1995, 121, No. 6, 667-675.

Discussion contributions on this paper should reach the editor by 1 April 2008 